\title{
Enfoques y desenfoques
}

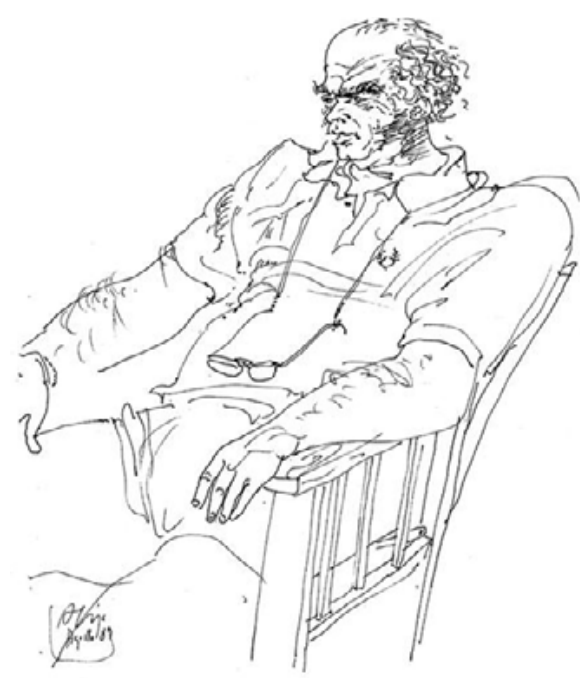

Victor Mestre: Estimado Dom Arturo Franco, em primeiro lugar quero agradecer o honroso convite que me propões. Congratulo-me que o próximo número da tua ilustre revista seja dedicado a Portugal, e sinceramente espero que a escolha dos que representarão a arquitectura portuguesa nessa vertente que pretendes, ou seja, na relação entre arquitectura vernacular e arquitectura contemporânea em Portugal, seja representativa das diversas formas de olhar e sentir essa articulação.

Os antecedentes históricos nesta área têm uma grande relevância na história da arquitectura portuguesa, de que recordarás certamente o magistral trabalho do arquitecto Fernando Távora, entre outros. Na actualidade essa relação está um pouco ausente ou, em alguns momentos, deixa transparecer um certo fio condutor com esse tempo anterior subtilmente renovado. Noutras situações temos a tentativa da renovação da arquitectura de terra que lentamente se vai desprendendo do formalismo traiçoeiro. Registo também o niilismo de alguns que, querendo estar em todas as frentes, propõem ensaios desligados de uma estrutura intelectual capaz de ordenar memória, tradição, contemporaneidade, aliada a uma actualização científica de materiais e tecnologia contemporâneas.

Este é um tempo de facto complexo e muito aliciante de se abordar. Poderá mesmo este teu projecto constituir um ponto fundamental de reflexão na construção da identidade da arquitectura portuguesa. Antes de me comprometer com este auspicioso projecto tenho que te confessar que estou profundamente empenhado em desmontar qualquer perspectiva niilista de star-system, em favor da seriedade de todos os que trabalham na nossa profissão de forma elevada e silenciosa em prol do bem comum, o principal desígnio da arquitectura.

Despeço-me de novo com um sincero agradecimento, cumprimentando-te e aproveito para enviar um abraço ao Fernando Vela que muito estimo.

Arturo Franco: Estimado Víctor: Te envío una lista de preseleccionados muy verde todavía...

Ha habido una confusión enorme. Te he enviado, por error, la lista de los descartados en una primera instancia. En un momento te envío la lista de arquitectos que estamos barajando. Siento mucho el descuido. Imagino que estarias bastante sorprendido...

VM: Caro Arturo Franco. Como combinado tenho estado a preparar o esboço do texto que me solicitaste e assim sendo envio-te as linhas gerais e ainda provisórias do que poderá ser o índice em síntese:

A influência do Inquérito à Arquitectura Popular em Portugal, na Arquitectura erudita no pós-guerra. Enquadramento histórico, nacional e internacional (texto ilustrado com fotos e desenhos representativos). Alguns autores ainda provisórios: Fernando Távora, Victor Figueiredo, Sérgio Fernandez, Manuel Tainha, Nuno Teotónio Pereira, Raul Chorão Ramalho, José Forjaz, António Veloso, Lixa Felgueiras, Álvaro Siza Vieira, etc.

Nostalgia, Citação e Memória da arquitectura vernacular na arquitectura contemporânea - período democrático. Da configuração da entidade espacio-funcional à expressão arquitectónica: Paulo Gouveia, João Nasi Pereira, José Gigante, Paulo David, José Bernardo Távora, Pedro Maurício Borges, Pedro Mendes, SAMI arquitectos, Back Gordon, João Mendes Ribeiro, Bárbara Delgado, Pedro Machado da Costa e Célia Lourenço Gomes, etc. (texto ilustrado com fotos e desenhos representativos). Selecção dos exemplos seminais. A seleccionar....Nota final sobre esses exemplos.

Caro Arturo Franco aguardo noticias tuas para poder progredir ou não... Abraço.

AF: Querido Victor: El planteamiento me parece muy, muy interesante. Tal vez yo añadiría, si lo crees oportuno, una mención especial a la relación de la arquitectura con el territorio (respeto e integración....), no solo con la arquitectura vernácula, también con el lugar. Solo si estás de acuerdo. Muchos de los arquitectos que citas así lo demuestran...

Te envío ahora por WeTransfer una selección de lo que llevamos por el momento a falta, probablemente, de atellier de Santos. Dime qué te parece la selección... recuerda que se trataba de elegir arquitectos de entre 30 y 50 años no excesivamente publicados... en progresión. Investigaremos algunos de los nombres que tú propones en el apartado contemporáneo, que no conocía... Saludos

VM: Caro Arturo. Confesso a minha surpresa e até um certo desconcerto com a escolha que enviaste. E antes de mais digo-te que considero todos os exemplos excelentes no âmbito da divulgação da arquitectura contemporânea portuguesa.

Contudo eu tinha intuído que o objectivo da escolha seria centrado na pesquisa/citação/miscisnação/influência directa e ou indirecta da arquitectura vernacular na arquitectura contemporânea portuguesa. Não só na perspectiva do Keneth Frampton, do Re- 
gionalismo Crítico, há muito em transição, mas sobretudo a partir de novas interpretações das culturas/arquitecturas locais, numa certa aproximação à integração cultural/paisagística/ecológica dos lugares, integrando necessariamente discursos filosóficos actuais num enquadramento universalista.

Fiquei assim com a percepção, após observar os exemplos enviados, que o tema é no fundo uma apresentação da actual arquitectura contemporânea que se faz em Portugal e que, volto a dizer, são exemplos de elevada representatividade, mas não encontro em nenhum deles qualquer leitura do vernacular no seu ADN. O que observo são diversas aproximações a uma revisão do moderno em que alguns casos quase se destacam por um neo-moderno abstracto, com maior ou menor influência do Siza Vieira, do Souto Moura ou mesmo já de outros seus sucessores, ou ainda de referências mais exteriores ao contexto português.

Caríssimo Arturo, desculpa o meu desabafo mas é sincero e respeitador da tua escolha, por isso te peço desculpa por não ter entendido o âmbito deste honroso convite, que muito gostaria de honrar e ou de participar de algum modo.

Os exemplos que te enviei são alguns entre outros possíveis, naturalmente que deixarão transparecer uma certa aproximação ao vernacular. Estes incorporam leituras do vernacular ou subliminarmente, ou integrando citações mais ou menos explícitas...ou ambas.

A abordagem teórica do texto que neste âmbito me propunha realizar, apesar de necessariamente condensado, deveria abordar as diversas formas que a arquitectura contemporânea teve/tem para "captar e ou capturar" o espírito, a alma do vernacular, como elemento estruturante ou como auxiliar de memória diferenciável da arquitectura erudita com outra filiação diversa, projectada para um determinado contexto, ou como uma determinada referencia, foi secamente seleccionada/integrada enquanto "adereço arquitectónico", descontextualizada de uma abordagem cultural.

Arturo, espero não estar a maçar-te com as minha concepções nesta área que poderão não ter qualquer enquadramento no que ambicionas legitimamente para o número da tua preciosa Rita. Por isso te peço, com toda a sinceridade, que te sintas num total à-vontade para comigo para procurares outro rumo. Estas palavras não significam que me esteja a descartar do que me solicitaste, pois respeito muito o teu trabalho enquanto Arquitecto e enquanto Editor, o que quero reafirmar é que tens todo o direito em me confirmares o meu equívoco e procurares outra pessoa, se for este o teu desejo garanto-te que não ficará qualquer mal entendido entre nós. Despeço-me com um grande abraço.

AF: Estimado Victor: Creo que no estamos tan distantes, salvo en algún ejemplo concreto, y que los dos queremos hablar de lo mismo. Tu planteamiento me parece el adecuado y lo que buscábamos. Tal vez no veamos exactamente de la misma manera el cómo esa actitud ha llegado hasta la arquitectura actual, pero eso es enriquecedor.

En rita_siempre hemos planteado dos partes diferenciadas dentro del país a estudiar:

1_Un texto teórico sobre lo que consideramos más representativo de la arquitectura del país, singularidad, identidad... (este es tu texto) Una lectura particular sobre un tema concreto, con pequeñas fotos al margen, ilustrativas.

2_Una selección editorial de las obras más representativas dentro de una manera de hacer las cosas. (Esta es una selección que hace la editorial). No tiene por qué tener que ver exactamente con el texto teórico. Se presentan las obras en 2 o 4 páginas.

Por eso entendemos que son dos apartados separados. Así, conociendo tu criterio y algunos de tus textos anteriores, te hemos propuesto escribirlo con libertad total.

En cuanto a la selección de arquitectos actuales que tú propones, compuesta entre otros por: Paulo Gouveia, João Nasi Pereira José Gigante, Paulo David, José Bernardo Távora, Pedro Maurício Borges Pedro Mendes, Sami arquitectos, Back Gordon, João Mendes Ribeiro, Bárbara Delgado, Pedro Machado da Costa e Célia Lourenço Gomes; hay varias coincidencias con la nuestra: Sami arquitectos, Pedro Machado da Costa e Célia Lourenço Gomes...(atelier de Santos). Creo que las listas son complementarias y no se contradicen.

Me ha sorprendido mucho, y bien, la vivienda de José Bernardo Tavora que no conocía y también Pedro Maurício Borges , João Mendes Ribeiro y, por supuesto, Paulo David, a los que ya conocía...

Tú puedes usar tus referencias y nosotros las nuestras sin contradicciones.

Nosotros hemos propuesto de momento: Barbas Lopes, Nuno Valentín, Brandao Costa (tal vez una arquitectura menos local y más universal, industrial, de la que podríamos prescindir en esta relación), Álvaro Fernandes (tal vez el más extraño de los elegidos pero creo que hay que mirarlo con cuidado y atendiendo a su relación con el territorio. Él se reconoce abiertamente alumno de Fernando Tavora. Tal vez podríamos prescindir de él en este proyecto, sin prejuicio de recuperarlo más adelante), Menos es mais, Sami, Ricardo Carvallo, Atelier de Santos...

Si lo ves oportuno, tú haces el artículo conforme hemos hablado y nosotros retiraríamos de la selección esos nombres que tal vez distorsionen el mensaje. Si estás de acuerdo continuamos. Un abrazo

VM: Caro Arturo. Agradeço o teu precioso esclarecimento e a tua confiança, concordo com a tua estratégia e portanto agora, mãos à obra. Trabalharei durante esta semana para te enviar um primeiro draft rapidamente.

Abraço.

\section{Victor Mestre}

Arturo Franco 